\title{
The Implementation of Mind Mapping on Chemical Bond Learning Assisted by Information Technology towards the Students' Learning Outcomes in Class X MIA 1 at SMA Negeri 1 Sindue
}

\section{*Awanda, Tahril \& Minarni Rama Jura}

Pendidikan Kimia/FKIP - Universitas Tadulako, Palu - Indonesia 94119

Received 24 June 2020, Revised 22 July 2020, Accepted 14 August 2020

doi: 10.22487/j24775185.2020.v9.i3.pp172-175

\begin{abstract}
This study aimed to determine the influence of the implementation of mind mapping on learning of chemical bonding assisted with information technology toward learning outcomes of students in the Class X1 Science at SMA 1 Sindue. This study was a quasi-experiment with non-randomized pretestposttest control group design. Sampling was based on special consideration (purposive sampling) with a sample of students of class X1 Science as the experimental class and class X2 Science as the control class. The instrument of this study was a test of learning outcomes. Data of the results was tested using statistical analysis of one-party t-test with prerequisite tests of normality and homogeneity tests. The data analysis obtained an average score of learning outcomes in the experimental class was 77.12 and in the control class was 67.6. Based on the hypothesis test with the t-test statistic of two parties obtained $t_{\text {count }}$ of 10.89 and $t_{\text {table }}$ of 1.95 at $\alpha 0.05$. In this case, $H_{1}$ was accepted and $H_{0}$ was rejected because $t_{\text {count }}$ was in the area of $H_{0}$ rejection. This showed that there were differences in students' learning outcomes through the implementation of mind mapping and conventional in learning of students in $10^{\text {th }}$ grade at SMA 1 Sindue.
\end{abstract}

Keywords: Mind mapping, information technology, learning outcomes, chemical bonding

\section{Pendahuluan}

Pendidikan merupakan pilar terpenting dalam kemajuan suatu bangsa, bahkan menjadi peran paling utama dalam kemajuan hidup manusia. Keadaan suatu bangsa tentunya sangat dipengaruhi dengan bagaimana kondisi manusia yang berada dalam bangsa tersebut. Pada dasarnya yang berperan dalam menjalankan suatu bangsa adalah orang-orang yang menempati bangsa itu sendiri. Hal inilah sangat tergantung dari pendidikan yang diperoleh dari orang-orang itu sendiri (Dewi dkk., 2014).

Di era globalisasi dan informasi ini, perkembangan media pembelajaran juga semakin maju. Penggunaan Teknologi Informasi (TI) sebagai media pembelajaran sudah merupakan suatu tuntutan. Walaupun perancangan media berbantuan TI memerlukan keahlian khusus, bukan berarti media tersebut dihindari dan ditinggalkan. Media pembelajaran berbantuan TI dapat berupa internet, intranet, mobile phone, dan CD room/flash disk (Muhson, 2010).

Suasana pembelajaran TI akan memaksa pelajar memainkan peranan yang lebih aktif dalam pembelajarannya. Pelajar membuat perancangan dan mencari materi dengan usaha, dan inisiatif sendiri (Yazdi, 2012). TI dapat meningkatkan kualitas dan jangkauan apabila digunakan secara bijak dalam pendidikan (Budiman, 2017).

Desain pembelajaran dari penerapan kurikulum 2013 harus menciptakan pola pembelajaran yang interaktif dan mengubah sistem pembelajaran yang terisolasi menjadi pembelajaran secara jejaring (Alep dkk., 2015).

Materi pelajaran kimia merupakan pelajaran wajib bagi siswa Sekolah Menengah Atas (SMA), tetapi kebanyakan siswa menganggap kimia adalah mata pelajaran sulit karena sebagian besar bahan kajian ilmu kimia penuh dengan konsep matematika yang kadangkadang tidak sederhana. Sehingga siswa sudah terlebih dahulu merasa kurang mampu untuk mempelajarinya (Fauziah dkk., 2013).

Salah satu pembelajaran kimia yang bersifat abstrak dan sulit dipahami siswa yaitu materi ikatan kimia. Materi ini terdapat terdapat konsep-konsep yang memerlukan pemahaman dan hafalan yang mendalam, seperti pemahaman siswa tentang ikatan kimia secara umum, kestabilan unsur, struktur lewis, ikatan ion dan ikatan kovalen (Nugraha dkk., 2013).

*Correspondence:

Awanda

e-mail: wardaawanda@gmail.com

(c) 2020 the Author(s) retain the copyright of this article. This article is published under the terms of the Creative Commons Attribution License 4.0, which permits unrestricted non-commercial use, distribution, and reproduction in any medium, provided the original work is properly cited. 
Hal ini disebabkan kurangnya daya serap siswa dan aktivitas membaca yang rendah. Ini juga diperburuk adanya beberapa siswa yang tidak mencatat materi pelajaran atau setelah mencatat tidak membuka atau jarang membaca catatannya kembali. Gejala inilah dikatakan siswa pasif, karena belajar dengan menghapalkan kalimat lengkap tidak akan efektif (Venisari dkk., 2015).

Dalam menyajikan materi kimia agar menjadi lebih menarik, guru harus memiliki kemampuan dalam mengembangkan metode mengajarnya sedemikian rupa sehingga tujuan pembelajaran yang diharapkan pada standar kompetensi dapat dicapai dengan baik (Sirhan dkk., 2015).

Atas dasar masalah yang dikemukakan diatas diperlukan inovasi pembelajaran berbeda yaitu dengan metode mind mapping. Dengan mind map siswa tidak perlu fokus untuk mencatat secara keseluruhan, siswa hanya mengetahui inti masalah, kemudian membuat peta pikiran sesuai kreativitasnya sendiri (Venisari dkk., 2015).

Mind mapping adalah suatu peta pikiran dengan menggunakan cara termudah untuk menempatkan informasi ke dalam otak dan mengambil informasi keluar otak, yang merupakan cara mencatat yang kreatif dan efektif (Lestari, 2018).

Hasil belajar adalah perubahan perilaku secara keseluruhan bukan hanya salah satu aspek potensi kemanusiaan saja. Hasil dari belajar adalah adanya perubahan dalam diri siswa, baik itu perubahan nilai akademik maupun perilaku dalam belajar (Lestari, 2018).

Hasil belajar peserta didik dalam aspek kognitif dapat meningkat dengan model pembelajaran mind mapping. Pernyataan ini berdasarkan penelitian yang telah dilakukan disalah satu SMA Negeri 5 tahun 2015-2016. Peningkatan ini terjadi karena selama pengajaran peserta didik terlibat aktif (Retnowati, 2018).

Salah satu tolak ukur berkembangnya kualitas pendidikan dapat dilihat dari hasil belajar siswa, karena hasil belajar mencakup semua hal yang dihasilkan dari pelaksanaan suatu pendidikan. Hasil belajar merupakan perubahan perilaku siswa akibat belajar. Perubahan itu diupayakan dalam proses belajar mengajar dapat mencapai tujuan pendidikan (Purwanto, 2013).

Menurut Asgari \& Mahdi (2013)

"learning outcomes emphasize there essential aspects of learning outcomes including cognitive, affective and behavior in order to prepare students for their social work and professional life" yang artinya bahwa hasil belajar menekan pada tiga aspek penting dari hasil belajar termasuk kognitif, afektif, dan perilaku dalam rangka mempersiapkan siswa untuk pekerjaan sosial dan kehidupan professional.

Untuk mencapai itu semua, diperlukan paradigma baru oleh guru dalam proses pembelajaran, dari yang semula pembelajaran berpusat paada guru menuju pembelajaran yang inovatif dan berpusat pada siswa (Gultom \& Juliawati, 2017).

Berdasarkan hasil observasi dan wawancara yang telah dilakukan dilakukan di SMA Negeri 1 Sindue menunjukkan bahwa pembelajaran kimia yang dilakukan masih berpusat pada guru khususnya materi ikatan kimia yang masih menggunakan motode ceramah sehingga siswa kurang melibatkan diri secara aktif dalam proses belajar mengajar.

Solusi untuk memecahkan permasalahan ini, perlu diupayakan penerapan pembelajaran yang dapat mengembangkan motivasi belajar dan keterampilan berpikir siswa diantaranya adalah mind mapping berbantuan teknologi informasi (TI).

Teknik mind mapping (peta pikiran) adalah teknik termudah untuk memahami masalah dengan cara mencatat yang kreatif, efektif, dan memetakan pikiran kita melalui gambar sederhana (Rahayu dkk., 2017). "In addition, the mind map helps students to assimilate new information, to think and to develop their conceptual schema. Mind mapping is a technique which enhances creativity and promotes individuals learning" yang artinya mind map membantu siswa berasimilasi informasi baru, untuk berpikir dan mengembangkan skema konseptual mereka, mind mapping adalah teknik yang meningkatkan kreativitas dan mempromosikan pembelajaran individu (Keles, 2012).

Teknik mind mapping adalah alat yang efektif untuk membantu siswa merencanakan dan mengatur tulisan mereka sekaligus mendorong mereka untuk mendapatkan pemahaman mendalam tentang hal-hal yang mereka tulis (Karim, 2018). Melalui teknik mind mapping diharapkan dapat meningkatkan motivasi belajar, daya imajinatif, dan kreativitas siswa (Sari dkk., 2016).

Tulisan ini dimaksudkan untuk mendeskripsikan tentang pengaruh penerapan mind mapping pada pembelajaran ikatan kimia berbantuan teknologi informasi terhadap hasil belajar siswa.

\section{Metode}

Desain penelitian ini adalah adalah desain non-randomized pretest posttest control group design. Kegiatan penelitian ini dilaksanakan di SMA Negeri 1 Sindue. Sampel dalam penelitian ini adalah siswa kelas X MIA 1 (27 siswa) sebagai kelas eksperimen dengan penerapan pembelajaran mind mapping berbasis TI dan X MIA 2 (28 siswa) sebagai kelas kontrol dengan penerapan metode pembelajaran konvensional. Teknik pengambilan sampel yaitu purposive sampling.

Berhubungan dengan penelitian yang dilakukan, data yang diperlukan adalah skor hasil belajar siswa. Instrumen yang digunakan dalam penelitian ini adalah tes pilihan ganda sebanyak 20 butir soal yang telah tervalidasi dan lembar 
observasi kegiatan aktivitas guru dan siswa. Tujuan penggunaan tes pilihan ganda yaitu untuk memperoleh hasil belajar siswa. Sedangkan lembar observasi aktivitas guru dan siswa bertujuan untuk mengamati pelaksanaan proses pembelajaran di kelas baik pada siswa maupun guru. Teknik analisis data dari penelitian ini adalah analisis statistika inferensial.

Analisis statistik inferensial digunakan untuk menganalisis hipotesis penelitian yang diajukan. Adapun teknik yang digunakan untuk menguji hipotesis penelitian adalah uji-t. Sebelum menganalisis hipotesis penelitian, maka dilakukan uji prasyarat berupa uji normalitas menggunakan uji chi kuadrat dan uji homogenitas varians menggunakan uji F (Sutianti dkk., 2018).

\section{Hasil dan Pembahasan}

Penelitian ini bertujuan untuk mengetahui pengaruh penerapan mind mapping pada pembelajaran ikatan kimia berbantuan teknologi informasi terhadap hasil belajar siswa.

Berdasarkan penelitian yang dilakukan, diperoleh data dari kelas ekperimen X MIA 1 dan kelas kontrol X MIA 2 seperti pada Tabel 1.

Tabel 1. Hasil penilaian aktivitas guru

\begin{tabular}{ccc}
\hline \multirow{2}{*}{ Uraian } & \multicolumn{2}{c}{ Kelas } \\
\cline { 2 - 3 } & Eksperimen & Kontrol \\
\hline Sampel & 27.00 & 28.00 \\
Nilai terendah & 55.00 & 55.00 \\
Nilai tertinggi & 90.00 & 85.00 \\
Skor rata-rata & 69.12 & 67.60 \\
Standar deviasi & 6.24 & 5.58 \\
\hline
\end{tabular}

Pengujian normalitas bertujuan untuk mengetahui apakah data yang diperoleh terdistribusi normal atau tidak. Kelas eksperimen, diperoleh hasil perhitungan data $\chi^{2}$ hitung $=7.67$ dan $\chi^{2}$ tabel $=7.81$. Hasil tersebut memenuhi kriteria data berdistribusi normal $\chi^{2}$ hitung $\leq \chi_{\text {tabel yaitu } 7.67}^{2}$ $<7.81$. Kelas kontrol diperoleh hasil perhitungan data $\chi_{\text {hitung }}^{2}=6.36$ dan $\chi_{\text {tabel }}^{2}=7.81$. Hasil tersebut memenuhi kriteria data berdistribusi normal

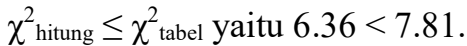

\section{Pengujian Homogenitas}

Salah satu syarat yang dalam pengujian homogenitas yang menyatakan perbedaan kedua kelas yang diambil sebagai sampel haruslah homogen yaitu dengan melakukan uji $F$ (kesamaan dua varian). Varians terbesar $=6.24$ sedangkan varians terkecil $=5.58$. Diperoleh nilai $\mathrm{F}_{\text {hitung }}=1.1$ dan $\mathrm{F}_{\text {tabel }}=2.12$. Maka data tersebut memenuhi kriteria data homogen yaitu $\mathrm{F}_{\text {hitung }}<$ $\mathrm{F}_{\text {tabel }}$ yaitu $1.1<2.12$.

\section{Pengujian Hipotesis}

Berdasarkan hipotesis dalam penelitian yaitu terdapat pengaruh penerapan mind mapping pada pembelajaran ikatan kimia berbantuan teknologi informasi terhadap hasil belajar siswa kelas X
MIA 1 SMA Negeri 1 Sindue. Maka pengujian hipotesis ini dilakukan dengan menggunakan ujit satu pihak. Secara matematis dapat dinyatakan sebagai berikut:

$\mathrm{H}_{0}$ : Hasil belajar dengan penerapan mind mapping berbantuan TI kurang dari atau sama dengan hasil belajar pada pembelajaran konvensional.

$\mathrm{H}_{1}$ : Hasil belajar dengan penerapan mind mapping berbantuan TI lebih baik dari hasil belajar pada pembelajaran konvensional.

Kriteria pengujiannya adalah terima $\mathrm{H}_{0}$ jika $\mathrm{t}_{\text {hitung }}$ $\leq t_{\text {tabel }}(1-\alpha),\left(\mathrm{n}_{1}+\mathrm{n}_{2}-2\right)$ dan tolak $\mathrm{H}_{0}$ jika $\mathrm{t}_{\text {hitung }}>$ $t_{\text {tabel }}(1-\alpha),\left(\mathrm{n}_{1}+\mathrm{n}_{2}-2\right)$. Berdasarkan hasil diperoleh $t_{\text {hit }}=10.57$ dan ini jelas berada didaerah penolakan $\mathrm{H}_{0}$. Jadi, $\mathrm{H}_{0}$ ditolak $\mathrm{H}_{1}$ diterima. Sehingga dapat disimpulkan bahwa penerapan mind mapping berbantuan TI dalam pembelajaran ikatan kimia lebih baik hasil belajarnya dibandingkan dengan pembelajaran langsung. Hal ini disebabkan karena metode pembelajaran mind mapping memiliki kelebihan dapat mengaktifkan seluruh otak memungkinkan kita fokus pada pokok bahasan, membantu menunjukkan hubungan antara bagian-bagian informasi yang saling terpisah, memberi gambaran yang jelas pada keseluruhan dan perincian, dan menyenangkan untuk dilihat, dibaca, dicerna dan diingat. TI juga memudahkan siswa memperoleh informasi terkait materi yang diajarkan oleh guru, berpartisipasi, berbagi, dan menciptakan sesuatu dengan mudah dan cepat (Wijayanti dkk., 2019).

\section{Kesimpulan}

Terdapat perbedaan pada hasil belajar siswa dengan menggunakan pembelajaran mind mapping berbantuan TI pada materi ikatan kimia. $\mathrm{Hal}$ ini dapat dilihat dari skor rata-rata posttest dari masing-masing kelas, yaitu pada siswa kelas eksperimen $=77.12$, dan siswa kelas kontrol $=$ 67.6. Hal tersebut diperkuat dengan analisis statistik dimana analisis uji-t diperoleh $t_{\text {hitung }}>t_{\text {tabel }}$ yaitu $10.57>1.95$ dengan taraf signifikan 0.05 dan derajat kebebasan, dk 53 .

\section{Ucapan Terima Kasih}

Penulis mengucapkan terimakasih kepada Fitriani Latahia, guru mata pelajaran kimia kelas $X$ SMA Negeri 1 Sindue dan adik-adik kelas X MIA 1 dan adik-adik kelas X MIA 2 SMA Negeri 1 Sindue yang turut membantu penulis sehingga penelitian ini berjalan dengan baik dan lancar.

\section{Referensi}

Alep, B., Walanda, D. K., \& Hamzah, B. (2015). Penerapan metode pembelajaran SQ3R berbantuan internet terhadap hasil belajar siswa kelas X pada materi sistem periodik unsur di SMA Labschool Palu. Jurnal Akademika Kimia, 4(1), 44-49. 
Asgari, M., \& Mahdi, B. (2013). Evaluating the learning outcomes of internasional students as educational tourisits. Journal of Business Studies Quartely, 5(2), 130-140.

Budiman, H. (2017). Peran teknologi informasi dan komunikasi dalam pendidikan. Jurnal Pendidikan Islam, 8(1), 31-43.

Dewi, N. L., Ida, B. P., \& Nurjaya, I. G. (2014). Analisis nilai-nilai pendidikan karakter novel sepatu dahlan karya kharisna pabhicara dan relevansinya terhadap pengajaran pendidikan karakter sekolah di indonesia. Jurnal Pendidikan Bahasa dan Sastra Indonesia, 2(1), 1-10.

Fauziah, N., Mohammad, M., \& Agung, N. (2013). Teams achievement division (STAD) menggunakan peta pikiran (mind mapping) peta konsep (concept mapping) terhadap prestasi belajar siswa pada materi pokok sistem periodik unsur siswa kelas $\mathrm{X}$ semester ganjil SMA Negeri Kebakkramat tahun pelajaran 2012/20. Jurnal Pendidikan Kimia, 2(2), 1-8.

Gultom, M., \& Juliawati, S. (2017). Pengaruh model pembelajaran mind maping terhadap hasil belajar siswa pada materi kingdom plantae di kelas X SMA Negeri 2 Rantau Utara. Jurnal Pembelajaran dan Biologi Nukleus, 3(2), 47-50.

Karim, R. A. (2018). Technology-assisted mind mapping technique in writing classrooms: An innovative approach. International Journal of Academic Research in Business and Social Sciences, 8(4), 1092-1103.

Keles, O. (2012). Elementary teachers' views on mind mapping. International Journal of Education, 4(2), 93-100.

Lestari, I. (2018). Penerapan model pembelajaran mind mapping dalam metode quantum learning untuk meningkatkan hasil belajar. Jurnal Pendidikan dan Pembelajaran, 3(3), $1-9$.

Muhson, A. (2010). Pengembangan media pembelajaran berbasis teknologi informasi. Jurnal Pendidikan Akuntansi Indonesia, 8(2), $1-10$.

Nugraha, A. N., Elfi, S. H., \& Mohammad, M. (2013). Efektivitas metode pembelajaran kooperatif think pair share yang dilengkapi media kartu berpasangan (index card match) terhadap prestasi belajar siswa pada materi ikatan kimia kelas X semester gasal SMAN 2 Karanganyar tahun pelajaran 2012/2013. Jurnal Pendidikan Kimia, 2(4), 174-181.

Purwanto. (2013). Evaluasi hasil belajar. Yogyakarta: Pustaka Pelajar.

Rahayu, E. L., Akbar, P., \& Afrilianto, M. (2017). Pengaruh metode mind mapping terhadap strategi thinking aloud pair problem solving terhadap kemampuan berpikir kreatif matematis. Journal on Education, 1(2), 271278.

Retnowati, T. (2018). Penerapan model pembelajaran tipe mind mapping untuk meningkatkan hasil belajar peserta didik pada mata pelajaran biologi tentang sistem regulasi di kelas XI IPA C SMA Negeri 5 Bogor. Jurnal Teknologi Pendidikan, 3(1), 1-19.

Sari, E. N., Saiful, R., \& Nur, R. U. (2016). Pengaruh model pembelajaran discovery learning dengan mind mapping terhadap hasil belajar siswa pada materi sel di SMA. Journal Unnes Science Education, 5(3), 1403-1407.

Sirhan, M., Solfarina, \& Ratman. (2015). Mind mapping dalam pembelajaran struktur atom pada siswa kelas X SMA Negeri 1 Palu. Jurnal Akademika Kimia, 4(3), 116-112.

Rodykara, I, K., Dibia, I. K., \& Renda, N. T. (2018). Pengaruh model pembelajaran snowball throwing berbasis penilaian kinerja terhadap hasil belajar IPA. International Journal of Elemantary Education, 2(3), 173182.

Venisari, R., Gunawan, \& Sutrio. (2015). Penerapan metode mind mapping pada model direct instruction untuk meningkatkan kemampuan pemecahan masalah fisika siswa SMP Negeri 16 Mataram. Jurnal Pendidikan Fisika dan Teknologi, 1(3), 193-198.

Wijayanti, N., Ersanghono, K., \& Sri, S. S. (2019). Pembelajaran berbasis digital di jurusan kimia FMIPA Unnes. Jurnal Inovasi Pendidikan Kimia, 13(1), 2318-2325.

Yazdi, M. (2012). E-learning sebagai media pembelajaran interaktif berbasis teknologi informasi. Jurnal Ilmiah Foristek, 2(1), 143152. 